\title{
Bibliografía de y sobre Adolfo Bioy Casares
}

\section{OBRAS DEL AUTOR}

Bioy Casares, Adolfo. Adversos milagros. Venezuela: Monte Avila, 1969. - Breve diccionario del argentino exquisito. (Con el pseudónimo Javier Miranda). Buenos Aires: Barros Merino Editor, 1971.

-. Caos. Buenos Aires: Viau y Zona," 1934.

- Diario de la guerra del cerdo. Buenos Aires: Emecé Editores, 1969. (Onceava impresión, Emecé Editores, 1973.)

- 17 disparos contra lo porvenir. (Con el pseudónimo Martín Sacastrú). Buenos Aires: Editorial Tor, 1933.

- La estatud casera. Con un dibujo de Silvina Ocampo. Buenos Aires: Editorial Jacarandá, 1936.

—. El gran serafín. Buenos Aires: Emecé Editores, 1967.

- El gran serafin Buenos Aires: Emecé Editores, 1968.

—. Guirnalda con amores. Buenos Aires: Emecé Editores, 1959.

- Historias de amor. Buenos Aires: Emecé Editores, 1972.

—. Historias fantásticas. Buenos Aires: Emecé Editores, 1972.

—. Historia prodigiosa. 1 ra. ed. México: Obregón, 1956.

-. Historia prodigiosa. Buenos Aires: Emecé Editores, 1961.

- Homenaje a Francisco Almeyra. Buenos Aires: Destiempo, 1954.

—. La invención de Morel. Prólogo de Jorge Luis Borges. Buenos Aires: Editorial Losada, 1940.

—. La invención de Morel. 2da. ed. Prólogo de Jorge Luis Borges. Buenos Aires: Sur, 1948.

—. La invención de Morel. Prólogo de Jorge Luis Borges. Buenos Aires: Emecé Editores, 1953.

- La invención de Morel. Prólogo de Jorge Luis Borges. Buenos Aires: Emecé Editores, 1968. 
- La invención de Morel. 2da. ed. Buenos Aires: Emecé Editores, 1968.

—. La invención de Morel. España: Alianza, 1972.

- La invención de Morel. 7ma. ed. Buenos Aires: Emecé Editores, 1972

—. La invención de Morel. 8va. ed. Buenos Aires: Emecé Editores, 1972.

—. El lado de la sombra. Buenos Aires: Emecé Editores, 1962.

- Luis Greve, muerto. Buenos Aires: Editorial Destiempo, 1937.

- Memoria sobre la pampa y los gaucbos. Argentina: Sur, 1970.

- La nueva tormenta, o La vida múltiple de Juan Ruteno. Buenos Aires: [La casa editora no está mencionada], 1935.

- La otra aventura. Buenos Aires: Editorial Galerna, 1968.

-. El perjurio de la nieve. Buenos Aires: Emecé Editores, 1944.

—. El perjurio de la nieve. Buenos Aires: Emecé Editores, 1946.

- Plan de evasión. Buenos Aires: Emecé Editores, 1945.

—. Plan de evasión. 2da. ed. Buenos Aires: Editorial Galerna, 1969.

- Prólogo. Buenos Aires: Biblos Editorial, 1929.

- El sueño de los héroes. Buenos Aires: Editorial Losada, 1954.

-_. El sueño de los béroes. Buenos Aires: Emecé Editores, 1969.

- La tarde de un fauno. Madrid: Separata de Cuadernos Hispanoamericanos, 1964.

—. La trama celeste. Buenos Aires: Editorial Sur, 1948.

—. La trama celeste. Buenos Aires: Editorial Sur, 1967.

\section{LIBROS DE CO-AUTORES}

Bioy Casares, Adolfo y Jorge Luis Borges. Crónicas de Bustos Domecq. Buenos Aires: Editorial Losada, 1967.

- Cuentos breves y extraordinarios. Buenos Aires: Editorial Raigal, 1955.

- Cuentos breves y extraordinavios. Buenos Aires: Rueda, 1967.

-. Cuentos breves y extraordinarios, Argentina: Dist. El Ateneo, 1968.

-. Cuentos breves y extraordinarios. Argentina: Rueda, 1970.

-Dos fantasias memorables. Buenos Aires: Oportet et Halreses, 1946.

—. Dos fantasías memorables. Argentina: Edicom, 1971.

—. Libro del cielo y del infierno. Buenos Aires: Sur, 1960.

- Los mejores cuentos policiales. 1ra. serie, Buenos Aires: Emecé Editores, 1943. 
- Los mejores cuentos policiales. 3ra. ed. Buenos Aires: Emecé Editores, 1947.

- Los mejores cuentos policiales. 1ra. serie, 3ra. ed. Buenos Aires: Emecé Editores, 1947.

—. Los mejores cuentos policiales 2da. serie, 2da. ed. Buenos Aires: Emecé Editores, 1951.

- Los mejores cuentos policiales. 2da. serie, 3ra. ed. Buenos Aires: Emecé Editores, 1956.

- Los mejores cuentos policiales. 4ta. ed. Buenos Aires: Emecé Editores, 1962.

- Los mejores cuentos policiales. 2da. ed. Buenos Aires: Emecé Editores, 1965.

—. Los mejores cuentos policiales. 5ta. ed. Buenos Aires: Emecé Editores, 1965.

_- Los mejores cuentos policiales. España: Alianza, 1972.

—. Un modelo para la muerte. Buenos Aires: Oportet et Halreses, 1946.

- Un modelo para la muerte. Argentina: Edicom, 1970.

- Los orilleros. El pardiso de los creyentes. Buenos Aires: Losada, 1955.

—. Poesía gauchesca. 1ra. ed. México: Fondo de Cultura Económica, 1955.

- Seis problemas para don Isidro Parodi. Palabra liminar de Gervasio Montenegro. Buenos Aires: Sur, 1942.

Bioy Casares, Adolfo y otros. Cuentos argentinos de ciencia ficción. [El lugar de publicación no está mencionado]: Tres Américas, 1967.

Bioy Casares, Adolfo, Silvina Ocampo y Jorge Luis Borges. Antología poética argentina. Buenos Aires: Editorial Sudamericana, 1941.

- - Antología de la literatura fantástica. Buenos Aires: Editorial Sudamericana, 1941.

- Antologia de la literatura fantástica. 3ra. ed. Buenos Aires: Editotorial Sudamericana, 1967.

Bioy Casares, Adolfo y Silvina Ocampo. Los que aman, odian. Buenos Aires: Emecé Editores, 1946.

\section{MisceláneA}

Quevedo, Francisco de. Prosa y verso. Selección de Jorge Luis Borges y Adolfo Bioy Casares. Buenos Aires: Emecé Editores, 1960.

Rojas, Fernando de. La Celestina. Prólogo de Adolfo Bioy Casares. Buenos Aires: Editorial Estrada, 1949. 
IV. Traducciones

Bioy Casares, Adolfo. Der Schveikrieg. Traducido por Karl August Horst. München: Nymphenburger, 1971.

- Diario da guerra do porco. Traducido por Vera Pedroso. Río de Janeiro: Editora Expressao e Cultura, 1972.

- Diario de la guerra al maiale. Traducido por Livio Bacchi Wilcock. Milano: Bompiani, 1971.

- Diary of the war of the pig. Traducido por Gregory Woodruff and Donald A. Yates. New York: McGraw-Hill, 1972.

- L'invention de Morel. Traducido por Armand Pierhal. Paris: R. Laffont, 1952.

- The invention of Morel and other stories from La trama celeste. Traducido por Ruth L. C. Simms. Ilustrado por Norah Borges de Torre. Prólogo de Jorge Luis Borges. Austin: University of Texas Press, 1964.

—. L'invenzione di Morel. Traducido por Livio Bacchi Wilcock: Milano: Bompiani, 1965.

- Journal de la guerre au cocbon. Traducido por Françoise Marie Rosset. Paris: Lafforet, 1970.

- Morels Erfindung. Traducido por Karl A. Horst. München: Nymphenburger Verlagshandlung, 1965.

- Morels uivinding. Traducido por Mariolein Sabaste Betacortu. Amsterdam: Meulenhoffreeses, 1972.

- Nouvelles d'amour. Traducido por Françoise Marie Rosset. Paris: Laffont, 1972.

—. Plan d'evasion. Traducido por Françoise Marie Rosset. París: Laffont, 1972.

- Il sogno degli eroi. Traducido por Livio Bacchi Wilcock. Milano: Bompiani, 1968.

Bioy Casares, Adolfo y Jorge Luis Borges. Chroniques de Bustos Domerq. Traducido por Françoise Marie Rosset. Paris: Denoël, 1970.

- Cielo e inferno. Traducido por Antonio Porta, Marcelo Ravoni, Franco María Ricci, Parma: [La casa editora no ha sido menciona. da], 1972.

- Extraordinary tales. Editado y traducido por Anthony Kerrigan. New York: Herder and Herder, 1971.

- Secbs Aufgaben für Don Isidro Parodi. Traducido por Liselott Reger. Frankfurt: M. S. Fischer, 1969. 
- Six problèmes pour don Isidro Parodi. Traducido por Françoise Ma. rie Rosset. Paris: Denoël, 1967.

- Sei problemi per don Isidro Parodi. Traducido por M. Vanna Brocca y Aldo Palazzi. Milano: [La casa editora no ha sido mencionada], 1971.

—. Zes Raddsels voor Parodi. Amsterdam: Van Ditmar, 1968.

\section{Crítica Sobre Adolfo Bioy Casares}

Alazraki, Jaime. "Las crónicas de Don Bustos Domecq". Revista Iberoroamericana, Año XXXVI (1970), pp. 87-93.

Bonet, Carmelo M. Historia de la literatura argentina. Dirigida por Rafael Alberto Arrieta. Buenos Aires: 1959, t. IV, pp. 240-241.

Borges, Jorge Luis. [Sobre Luis Greve, muerto]. Sur, 39 (diciembre, 1937), pp. 85-86.

-. [Sobre El sueño de los béroes]. Sur, 235 (julio-agosto, 1955), pp. 88-89.

García, Germán. La novela argentina: un itinerario. Buenos Aires: 1952, p. 221.

- [Sabre Antología de la literatura fantástica]. Sur, 81 (junio, 1941), pp. 78-80.

González Lanuza, Eduardo. [Sobre La invención de Morel]. Sur, 75 (di. ciembre, 1940), pp. 159-161.

Kovacci, Ofelia. Adolfo Bioy Casares. Antología, esbozo biográfico y selección por Ofelia Kovacci. Buenos Aires: Ediciones Culturales Argentinas, Ministerio de Educación y Justicia, Dirección General de Cultura, 1963.

Mac Adam, Alfred J. "El espejo y la mentira, dos cuentos de Borges y Bioy Casares". Revista Iberoamericana, Año XXXVII, No. 75 (1971), pp. 357-374.

Mastronardi, Carlos. "Dos obras de Adolfo Bioy Casares". Sur, 179 (septiembre, 1949), 72-75.

Pezzoni, Enrique. "Bioy Casares, Adolfo", Enciclopedia de la literatura argentina. Buenos Aires: Editorial Sudamericana, 1970, pp. 90-95.

Roggiano, Alfredo A. "Bioy Casares, Adolfo", Diccionario de la literatura latinoamericana. Argentina. Segunda Parte. Washington. Unión Panamericana, 1961, pp. 248-251.

Rosales, César. "Dos obras de Adolfo Bioy Casares". Sur, 179 (septiembre, 1949), pp. 75-79. 
Sábato, Ernesto. [Sobre Plan de evasión]. Sur, 133 (noviembre, 1945). pp. 67.69.

Soto, Luis Emilio. Historia de la literatura argentina. Dirigida por Rafael Alberto Arrieta. Buenos Aires, 1959, t. IV, pp. 401.

Zum Felde, Alberto. Indice critico de la literatura bispanoamericana: La narrativa. México: 1959, p. 495.

RaQuel Puig Zaldívar

Miami University 